\title{
Malignant presternal goitre
}

\author{
TL Chow *, Wilson WY Kwan, Joyce YH Hui
}

\section{A B S T R A C T}

Goitres usually enlarge and descend caudad into the substernal space and are not palpable. We report on a patient whose goitre spread downward but anterior to the sternum. The thyroid mass was subsequently removed and was proven to be a papillary thyroid carcinoma. The mechanism by which a presternal goitre develops is probably due to invasion and erosion of the strap muscles and the cervical linea alba. The clinical implication of this presentation is complete extirpation of the presternal goitre with a cuff of the strap muscles.
Hong Kong Med J 2014;20:156-7

DOI: 10.12809/hkmj133946

${ }^{1}$ TL Chow *, FRCS (Edin), FHKAM (Surgery)

${ }^{1}$ WWY Kwan, MRCS

2 JYH Hui, FRCR, FHKAM (Radiology)

\section{Department of Surgery}

2 Department of Diagnostic Radiology and Organ Imaging

United Christian Hospital, Kwun Tong, Hong Kong

* Corresponding author: tamlinc@yahoo.com

\section{Introduction}

When goitres enlarge, they can extend beyond the boundary of the neck. Since the thyroid gland resides beneath the pretracheal fascia and the strap muscles and their attachments are connected to the top of the manubrium, goitres usually migrate down into the superior mediastinum. Substernal goitres can occur in $8.4 \%$ patients undergoing thyroidectomy. ${ }^{1}$

We have treated a patient with a malignant goitre, which spread exceptionally to the presternal region. Herein we report this unusual presentation of an extra-cervical extension of a thyroid mass and stress its association with malignancy.

\section{Case report}

A 50-year-old man presented to our out-patient clinic in January 2012 with an enlarging anterior neck mass for the past 3 years. He experienced mild pain which prompted him to seek medical advice. A dumb-bell-shaped mass was found over his anterior neck. The upper portion of the mass was about $4.5 \mathrm{~cm}$ in diameter and located at the suprasternal region. The lower portion was $3.5 \mathrm{~cm}$ in diameter and resided anterior to the sternum, about $3 \mathrm{~cm}$ from the upper border of manubrium (Fig 1). The whole mass migrated upward when patient swallowed which signified its thyroid origin.

Thyroid function test results were normal. Computed tomography 4 weeks later showed an isthmic thyroid mass $(3.7 \times 2.8 \times 3.4 \mathrm{~cm})$ containing micro- and macro-calcifications. The lower component of the dumb-bell-shaped mass was anterior to the sternum (Fig 2), and there was no substernal extension.

The patient was very keen to undergo surgery, but he declined fine-needle aspiration of the mass.

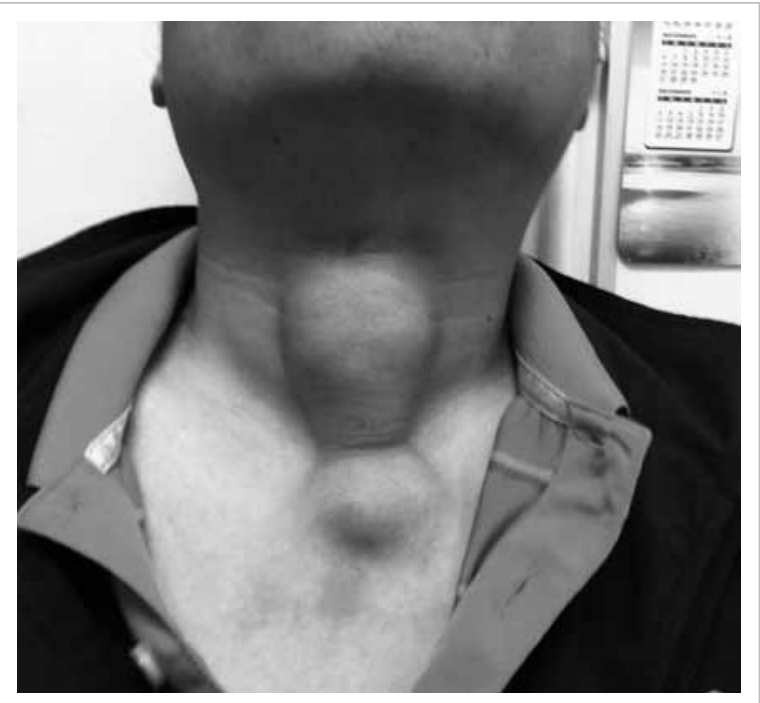

FIG I. The dumb-bell-shaped thyroid mass is shown. The inferior component extends inferiorly into the subcutaneous area anterior to the sternum

Total thyroidectomy with a collar incision was performed 3 weeks later. The $4.5 \times 5 \mathrm{~cm}$ isthmic thyroid mass passed through the midline fascia (between the strap muscles) and reached the presternal area. The muscle attachments of the strap muscles were at their normal positions on the manubrium. Total thyroidectomy including the entire dumb-bell mass en bloc with surrounding strap muscles and deep fascia was performed.

Histopathology revealed papillary thyroid carcinoma in both the superior and inferior components of the dumb-bell mass. The resection margin was clear. Postoperative radioactive iodine ablation $80 \mathrm{mCi}$ was given 5 months after the initial 


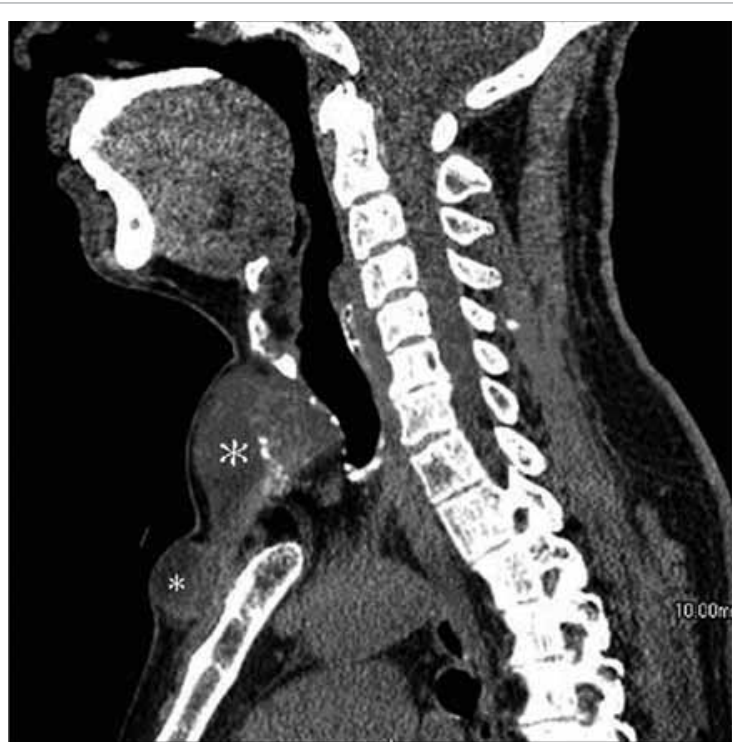

FIG 2. Pre-contrast, sagittal reformatted computed tomographic image demonstrates that the nodule contains coarse as well as micro-calcifications. The dumb-bell-shaped components of this lesion are marked by asterisks. The lower component was anterior to the sternum

presentation (about 10 weeks after surgery). The thyroglobulin level during thyroxine withdrawal was $<1.0 \mu \mathrm{g} / \mathrm{L}$, and there was no evidence of tumour recurrence.

\section{Discussion}

Substernal goitre is uncommon. Presternal goitre is even rarer. We searched the literature in MEDLINE and came across only two reported cases. The first reported by Raman and Nair ${ }^{2}$ in 1999 was a papillary thyroid carcinoma. The second described by Brilli et $\mathrm{al}^{3}$ in 2007 was a benign nodular goitre. We report this third case of a presternal goitre, which was also a papillary thyroid carcinoma. Therefore, if a thyroid mass spreads presternally, malignancy should be suspected. In our patient, malignancy was not suspected initially due to little knowledge about presternal goitres at that time. Therefore, an intraoperative frozen section was not obtained. We now realise the high risk of malignancy for this entity, and that preoperative fine-needle aspiration cytology or intra-operative frozen section examination should be performed in all such cases, and better informed consent regarding surgery should be obtained.

\section{胸骨前惡性甲狀腺腫}

周譚連、關偉賢、許懿馨

甲狀腺腫通常會變大並降尾側入胸骨後間隙, 且未能用手觸摸到。本 文報告一名病人的甲狀腺腫向下曼延, 但傾向胸骨的前方。其後為病 人移除甲狀腺灶, 並證實是乳頭狀甲狀腺癌。胸骨前甲狀腺腫的出現 可能是由於帶狀肌和頸白線的侵入及侵蝕。這病例顯示可替有關的病 人完整地一併切除胸骨前甲狀腺腫和帶狀肌。

Moreover, the extent of operation can also be more appropriately determined. In addition, preoperative imaging yielding micro-calcification in the goitre as well as presternal extension, or both should heighten the possibility of an underlying papillary carcinoma.

The mechanism resulting in the more common substernal goitre was speculated to the negative intrathoracic pressure during inspiration and the downward pull of gravity. ${ }^{4}$ By contrast, presternal migration of a malignant thyroid mass (as in our patient) was probably due to tumour erosion of the cervical linea alba between the strap muscles. Prompt investigation with imaging and fine-needle aspiration therefore seems imperative to make an accurate diagnosis and offer early therapy. Such patients should be advised to undergo total thyroidectomy. Notably, the thyroid masses should be removed en bloc with the adjacent strap muscles in order to achieve a clear resection margin.

Presternal goitre is rare and likely to represent thyroid malignancy eroding the cervical linea alba and strap muscles. Total thyroidectomy including a cuff of strap muscles encircling the mass should be performed to ensure complete tumour extirpation.

\section{References}

1. Chow TL, Chan TT, Suen DT, Chu DW, Lam SH. Surgical management of substernal goitre: local experience. Hong Kong Med J 2005;11:360-5.

2. Raman A, Nair A. Presternal extension of a malignant thyroid swelling. Aust N Z J Surg 1999;69:241-2.

3. Brilli L, Guarino E, Ghezzi M, Carli AF, Occhini R, Pacini F. Multinodular goiter of unusual shape and location. Thyroid 2007;17:693-4.

4. Singh B, Lucente FE, Shaha AR. Substernal goiter: a clinical review. Am J Otolaryngol 1994;15:409-16. 